\title{
SEDIMENTARY STRUCTURES GENERATED ON THE FORESHORE BY MIGRATING RIDGE AND RUNNEL SYSTEMS ON MICROTIDAL AND MESOTLDAL COASTS OF S. SPAIN
}

\section{C.A. DABRIO}

Dep. de Estratigrafia, Facultad de Ciencias, Universidad de Granada, Cronada (Spain)

(Received August 10,1981; revised and accopted November 30,1981 )

\section{ABSTRACT}

Dabrio, C.J, 1982. Sedimentary structures generated on the foreshore by migrating ridge and runnel systems on microtidal and mesotidal coasts of $\mathrm{S}$. Spair

The migration of ridge and rumnel systems on microtidal coasts is a rather simple process starting with the formation of a ridge at the upper shoreface after storms and its migration landwards until it welds onto the berm. This results in an ideal sequence of structures which includes (from bottom to top): cross-laminated sands (runnel facies); cross-bedded sands with local discontinuity surfaces (ridge facies); and even-laminated sands (berm facies). Larger tidal range and higher wave activity on mesotidal coasts induce a more differentiated pattern. At early stages of accretion, the ridge is covered at high tide and exposed at low lide. Swash accumulates a secondary bar of coarse sediment during low water that is removed and incorporated in the slip face of the ridge by avalanching during rising tides. At high tide, large amounts of finer sediment are brought by wayes and deposited on top of the ridge and in the slip face, generating fining-upward sequences. Erosional low-angle discontinuity surfaces develop during falling tides. Within the runnel, longshore currents are strong enough to build up small megaripples with crests roughly normal to the shoreline and waves induce wave ripples with crests more or less parallel to the shoreline. At later stages of accretion, the ridge is submerged mainly during spring high tide. After the runnel has been filled up, a vertical growth of the new berm occurs associated with fining-upward sequences due to decreasing energy and shoreward shifting of swash zones, during the transition from neap to spring tides. The restiting ideal sequence of sedimentary structures is larger and better differentiated than those described for microtidal and tidelex coasts.

\section{INTRODUCTION}

The inner structure generated by progradation of the foreshore is widely considered (Reineck and Singh, 1973; Reading, 1978) to consist of parallel lamination dipping gently seawards, with. subtle truncation planes dividing the laminations into discrete sets which are due to repeated cycles of erosion 
and deposition associated with varying depositional slopes.

Ridge and runnel development and migration can significantly modify this unimodal picture by incorporating other sedimentary structures such as high. angle cross bedding, cross lamination and low-angle cross bedding which may be preserved in accretional coasts (Doeglas, 1954; Wunderlich, 1972; Roep et al., 1975; Van den Berg, 1977; Hine, 1979; Beets et al., 1981). The aim of this paper is to deal with: (a) the sedimentary structures left behind by ridge and runnel systems during their landward migration and final welding onto the backshore; (b) their sequential arrangement; and (c) the sedimentary processes responsible for the changes observed. The influence of tidal range and coastal energy on the dimension and complexity of the structural content of such sequences will be considered in detail.

STUDY AREA

This paper is based on detailed observations carried out along the coasts of the Gulf of Cádiz and Bay of Mazarón (Fig. 1). The coast of Mazarrón is of the low-energy micro-tidal type: wave heights are about $20 \mathrm{~cm}$ (up to 60 $\mathrm{cm}$ in rough weather), and wave periods $3-3.5 \mathrm{sec}$. The tidal range is only $10 \mathrm{~cm}$, but can reach $20 \mathrm{~cm}$ by wind setup. Sediment along the coast is medium sand (Dabrio and Polo, 1981).

The coast of the Huelva Province, along the Gulf of Cadiz is subjected to medium to low energy: $75 \%$ of waves are less than $50 \mathrm{~cm}$ high and only $7 \%$ are higher than $1 \mathrm{~m}$; wave periods range between $4-7 \mathrm{sec}$ (fair weather) and $10-12 \mathrm{sec}$ (storms). Tides range between $1.3 \mathrm{~m}$ (neap tides) and $3.5 \mathrm{~m}$ (maximum spring tides) which makes it a mesotidal coast. Sediment along the beach is medium to coarse sand (Dabrio et al., 1980).

Because of the differences in tidal range and wave energy, the ridges are higher (up to 1.3 versus $0.20 \mathrm{~m}$ ) and migrate slower ( $5-8$ weeks versus $6-8$ days to weld onto the berm) in the Gulf of Cadiz than in the Bay of Mazarrón. This is in agreement with the results from Davis et al. (1972) who compared meso- and micro-tidal coasts.

Storms or strong swell usually cause a planing-off of the beach profile and a degradation of the foreshore. The material which is set free during this process is transported to the upper shoreface (beach terminology according to Reineck and Singh, 1973). As the highenergy conditions wane, a ridge is formed which, during the successive fair weather period, moves upshore and finally welds onto the backshore where it forms a berm. High-energy conditions may remove this berm partly or completely (Fig. $2 \mathrm{~A}$ ). The morphological changes associated with the origin and development of ridge and runnel systems have been studied in detail by Hayes and Boothroyd (1969), Hayes (1972), Owens and Frobel (1977) and Dabrio and Polo (1981) on beaches, and by McCave and Geiser (1978) on intertidal flats. The migration of ridges across the foreshore gives rise to changes of surface morphology, type and regime of flow and the internal structures developed at a given point. These 


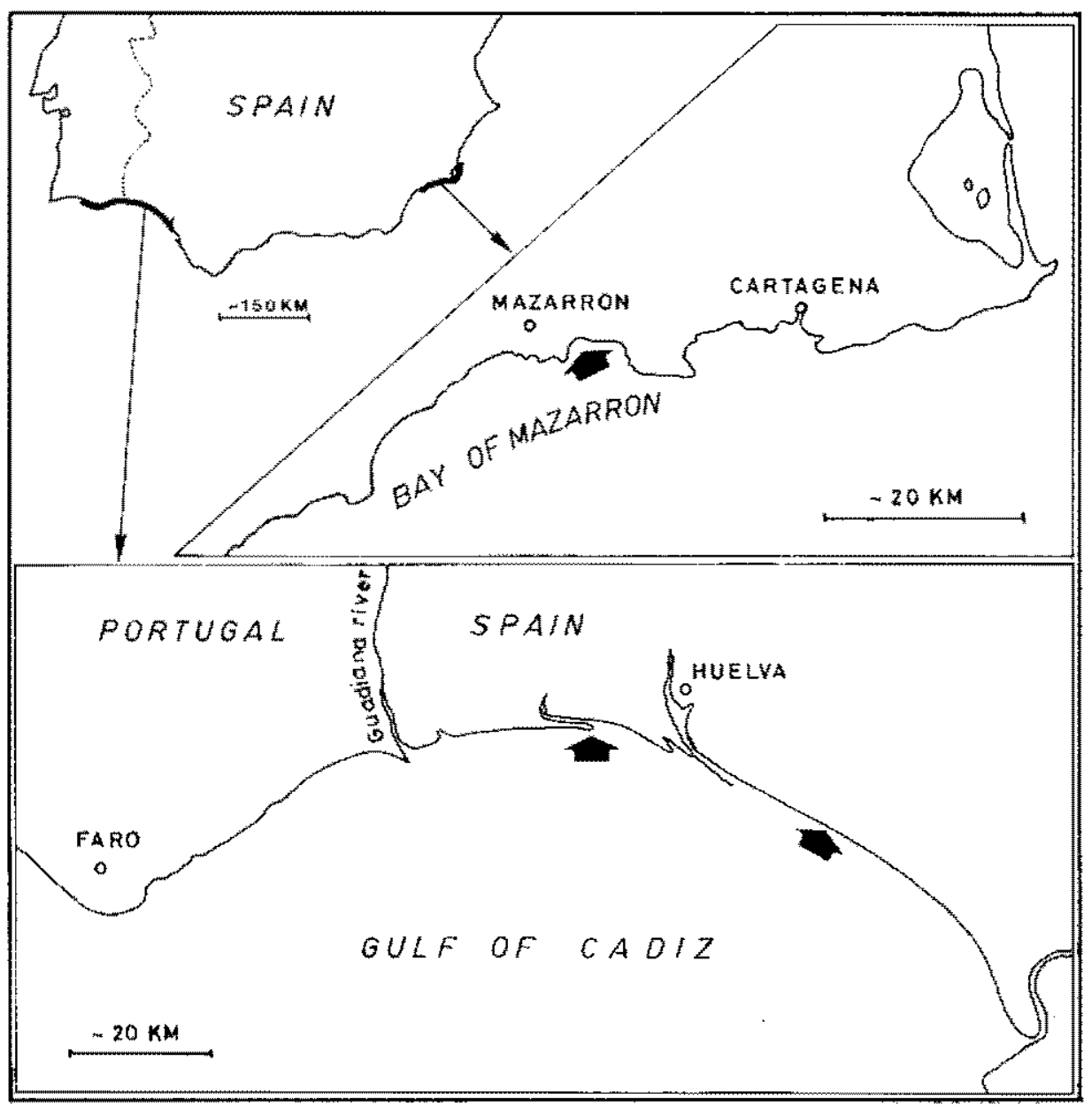

Fig. 1. Location maps of the coasts studied. Arrows indicate the places where detaled work was carried out.

structures were studied in trenches dug down to the local water table. Iacquer peels were made at selected localities. Observation periods, mainly restricted to fair weather, started in 1977 at Mazarrón and in 1979 at Gulf of Cádiz.

\section{MICROTIDAL COAST (MAZARRON BAY)}

Small ridges, $20-30 \mathrm{~cm}$ high, which actively migrate landward, occur (Fig. 2 ). The ridge, together with its leeside runnel, develops in the upper shoreface under conditions of asymmetric oscillatory flow. The ridge lies under lower or upper flow conditions depending on water depth and wave energy. 
The runnel invariably is subjected to a lower flow regime. Avalanching down the lee face of the ridge results in high-angle cross bedding that steps on the rumnel facies largely consisting of cross-laminated sands. The top of the ridge

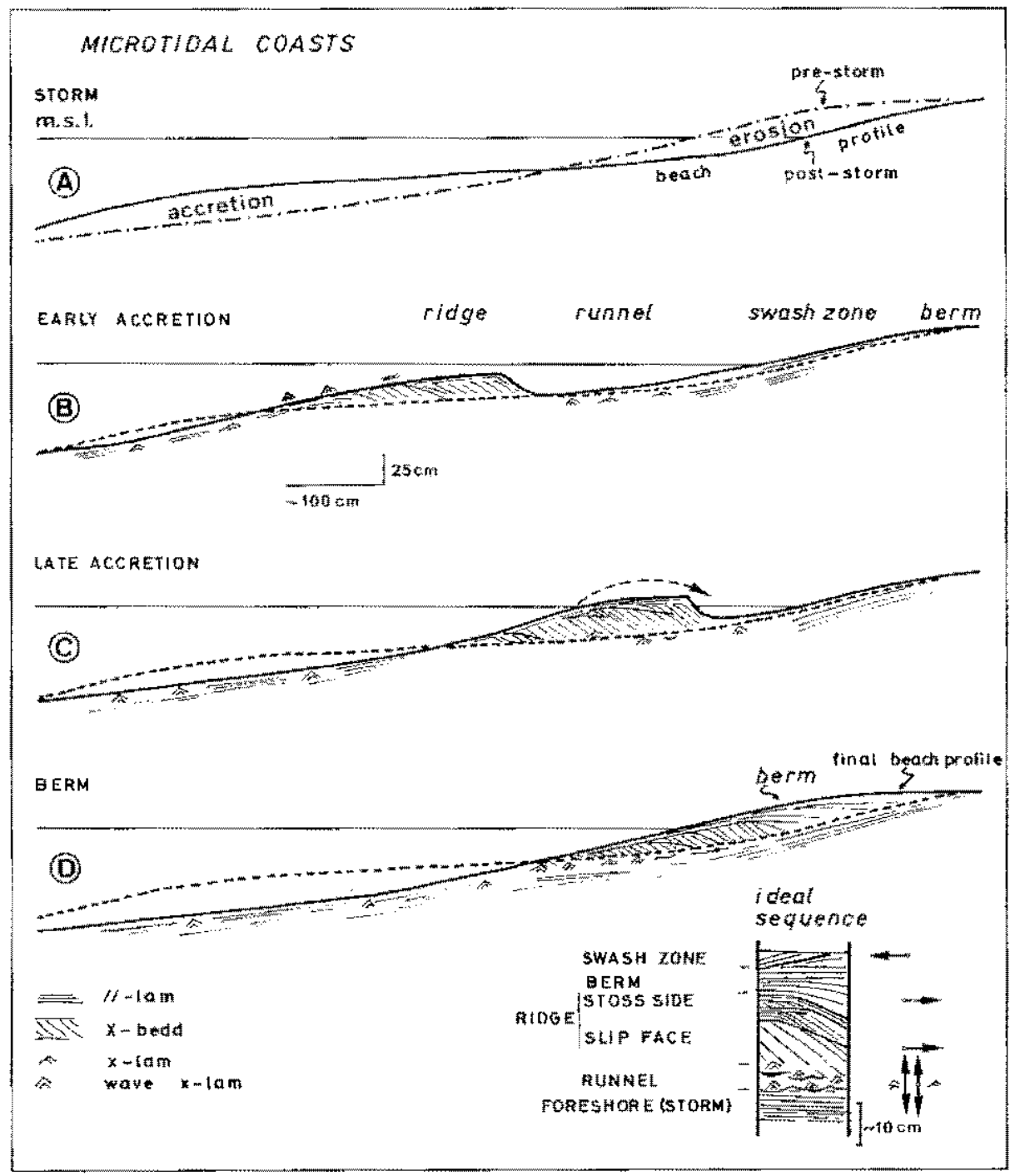

Fig. 2. Migration of ridge and runnel systems in micro-tidal coasts. Beach profile is strongly modified by storms because of erosion of the foreshore and deposition on the upper shoreface (A). Ridges form at the upper shoreface after storms (B) and migrate landward (C) to weld on to the berm (D). The ideal sequence originated is also shown with arows indicating dipping of laminae. Key: $X$-bedd; cross bedding; $X$-lam; current-ripple cross lamination; wave X-lam: wave-ripple cross lamination. Dotted lines superimposed on profiles $B, C$ and $D$ indicate the post-storm beach profile, 
is usually reworked because of the development of more or less asymmetrical wave ripples and upper flow regime plane bed (Fig. 2B).

In a more mature stage of development, when the ridge has migrated to a position on the foreshore, the runnel is largely under a unidirectional lower flow regime while the ridge itself is still under an oscillatory upper flow regime. Structures encountered in the ridge are essentially the same as those from the previous stage but for the occurrence of discontinuity surfaces separating laterally successive bundles of cross bedding. These surfaces are formed by changes of water level, wave energy and backwash action which make themselves better felt in the extreme shallow water (Fig. 2C).

When the ridge welds onto the berm, the runnel is filled with sand and vertical accretion of this new part of the berm takes place. The internal structure consists of horizontal or slightly landward-inclined parallel lamination. The newly formed berm is largely emergent and exposed to high-tide swash action under upper flow regime conditions. Backwash erosion cuts the seaward side of the berm, generating seaward-inclined parallel lamination (Fig. 20).

An idealized sequence (Fig. 2) would include three facies from bottom to top: (1) cross-laminated (both by wave and current ripples) sands, corresponding to runnel deposits; (2) landward-directed cross-bedded sands, containing some discontinuity surfaces, corresponding to the process of migration of the ridge over its runnel; and (3) parallel-laminated sands that partially dip opposite to the cross bedding, representing the welding of the ridge onto the berm.

\section{MESOTIDAL COAST (GULF OF CADIZ)}

Here, larger swash bars, up to $1.5 \mathrm{~m}$ high, form on the low-tide terrace and migrate landward across the foreshore to weld onto berm. The whole run takes about $6-8$ weeks.

As ridges climb up the foreshore, there are several modifications of the hydraulic system and flow regime, because of the continuously changing water level related to diumal and bi-weekly (neap-spring) tidal cycles. At high tide, the hydraulic system and flow regime are similar to those described for the early accretion stages in microtidal coasts. At low tide, however, they are similar to those of the late accretion stages. These short-term changes are superimposed upon the longer-term changes related to the migration of the bar. In this way a thicker and more differentiated sequence of sedimentary structures occurs (Fig. 3) as compared to micro-tidal or tideless coasts.

At early stages of accretion, when the ridge stands on the lower foreshore, it remains submerged during the longer part of the semidiurnal tidal cycle (Fig. 3A). For the rest of the cycle, the bar is emergent and swash action accumulates coarse sediment (shells and skeletal fragments) forming a small secondary bar on the stoss side of the ridge. As flood sets in, the small bar is 


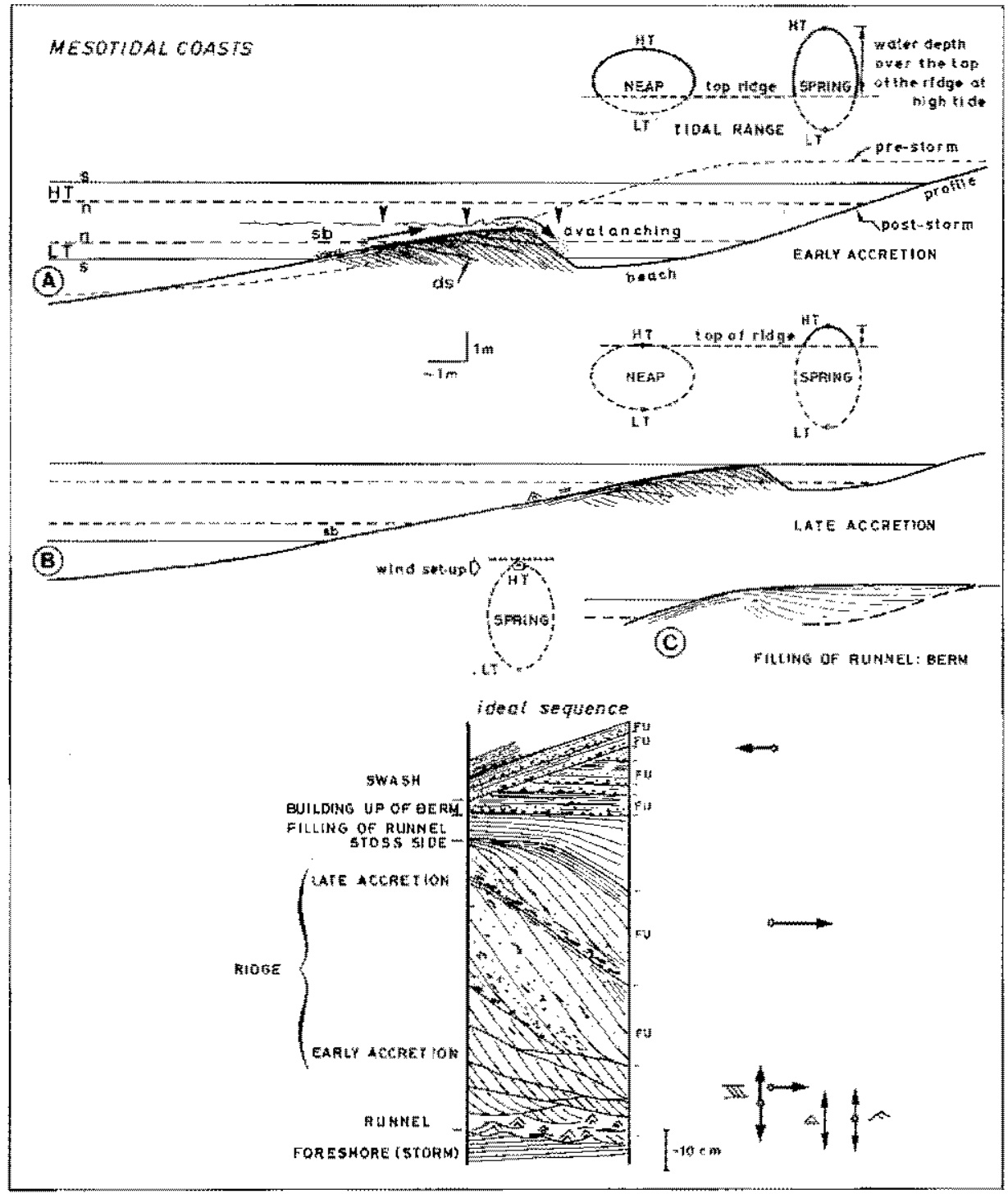

Fig. 3. Ridge and runnel migration and resulting sedimentary structures for mesotidal coast. At an early stage of accretion (A) the ridge is covered at high tide (HT) both during spring (s) and neap (n) tides and exposed at low tide $(L T)$. Swash induces a secondary bar of coarse sediment $(s b)$ during low water, that is removed and incorporated in the slip face of the ridge by avalanching during rising tide. At high tide a lot of finer sediment is brought in by waves and deposited on top of the ridge and on the slip face (vertical arrows). In this way, fining upward sequences $(F U)$ are generated. Erosional low-angle discontinuity surfaces (ds) develop during falling tide. At late stages of accretion (B) the ridge is submerged mainly during spring high tide. After the runnel has been filled up (C), a vertical growth occurs only during exceptionally high tides, especially if combined with wind setup. Fining-upward sequences $(F U)$ are common due to decreasing energy and shoreward shifting of swash zones over the crest of the ridge and berm during the transition from neap to spring tides (see text). Arrows indicate dipping of laminae. 
removed and its sediment pushed over the top of the ridge and incorporated in the slip face as foreset laminae of large-scale cross bedding. As flood tide proceeds, large amounts of finer sediments are brought to the ridge top and onto the slip face. The resultant decrease in grain size can often be recognized in the successive laminae deposited during a tidal cycle forming finingup microsequences which represent the decreasing energy related to the increasing water depth over the crest of the ridge as tide floods (Fig. 3). In many cases the foreset laminae also show a thinning-up arrangement.

At high tide, wave ripples with various crest patterns and sizes (similar in shape but larger than those described for microtidal coasts by Dabrio and Po$10,1981)$ tend to cover the ridge and rework its top; however, they fail to have much effect as they are removed again during the successive stage. Towards low tide, the shallowing above the ridge causes a change from lower to upper flow regime and the building of a plane bed, rhomboid megaripples, and local antidunes that result in parallel lamination.

At low tide, the ridge is emergent and waves built up in the water ponded landward of the ridge can produce an erosive smoothing of its top. This process is recorded as a low-angle discontinuity surface which separates successive bundles of high-angle foresets (see also Hine, 1979).

Thus, high-angle cross bedding topped by parallel lamination and discontinuity surfaces is the structure found on the ridge.

Within the runnel, longshore currents are strong enough to build up small megaripples with crests more or less normal to the shoreline. Waves induce wave ripples with crests more or less parallel to the shoreline. Local mud drapes and concentrations of heavy minerals are also present.

At late stages of accretion, the ridge climbs high up the foreshore and becomes larger and longer emergent. It is drowned mainly during spring high tides, and, to a lesser degree, during the higher neap tides (Fig. 3B).

Sedimentary processes are similar to those of the early stages of accretion, however, the duration of submergence is shorter and water depth over the ridge at high tide is smaller. At low tide, here also a small secondary bar of coarser material accumulates and is removed as water level rises, etc. (cf. description under early stages of accretion). Fining-up microsequences of the same kind as described for the early accretion stages are formed but vertical accretion of the bar becomes increasingly important at late stages of accretion (Fig. 4). As ebb progresses the ridge gradually emerges and its crest becomes subjected to partial erosion by waves. This leads to discontinuity surfaces less inclined than the foreset laminae.

The runnel is flooded at very high tide only. If, afterwards, the water table drops below the level of the runnel floor, fines and some organic matter are again deposited. Silting up of the runnel is accelerated at this stage because of the weakness of the longshore and drainage currents which have almost no time to develop. As a result, the low-angle cross-bedded and parallel-laminated sands deposited at high tide on the slip face will be preserved (Fig. 3C). The filling of the runnel causes the ridge to weld onto the berm 


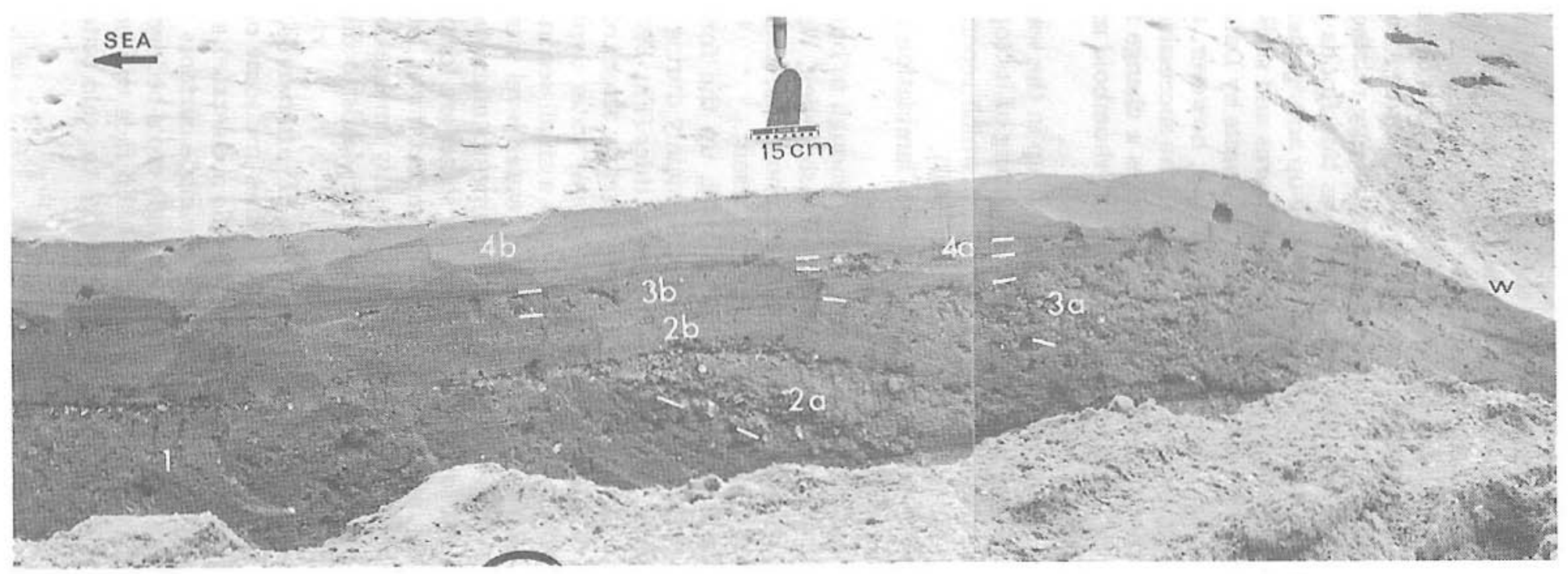

Fig. 4. Trench dug across a ridge at late stage of accretion. Sets of cross-bedded coarse sand and skeletal debris (1, 2a, $3 a)$ alternate with parallel-laminated medium sands $(2 b)$. Cross bedding forms during rising tide when the ridge is covered by water and coarse sediment swept from secondary bars (Fig. 3) is moved over the crest of the bar and incorporated in the slip face. Parallel-laminated sands represent the deposition of large amounts of finer sediments that are mobilized during high tide. Decrease in grain size is clearly visible both upward and landward. Truncation surfaces are not always prominent. Note water-level marks $(w)$ in the slip face. 


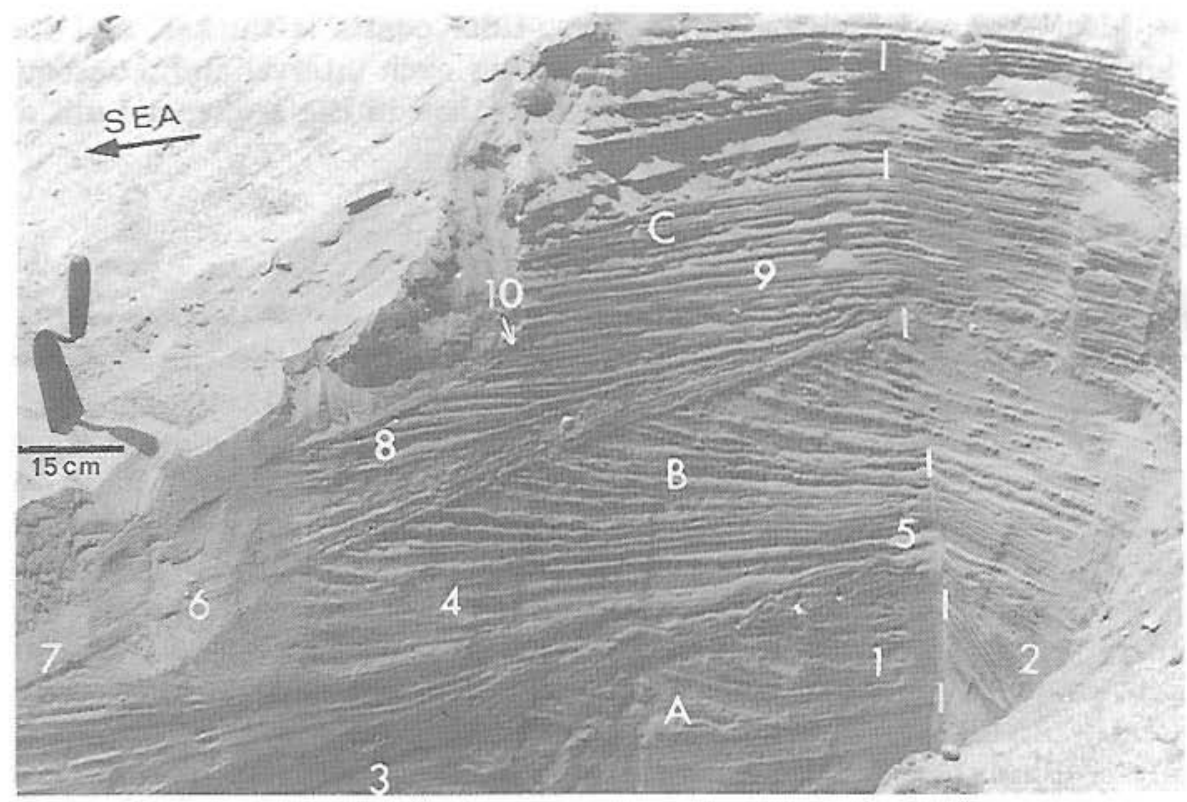

Fig. 5. Trench dug in the berm showing three episodes of ridge and runnel development. A corner of the trench is marked by a vertical dashed line. The left wall is normal to the ridge crests and the right one, parallel to them. The lower unit $(A)$ consists of high-angle $\left(13-23^{\circ}\right)$ cross-bedding (1) generated by a migrating ridge, and median-to-small-scale cross bedding (2) formed by megaripples migrating within the runnel. Part of the topset is still preserved below the erosional surface (3). Unit $B$ (centre) consists of cross bedding ( 4 , ridge facies) with foreset laminae tangential to the bottom, reworked by wave-ripples (5) within the runnel. A truncation surface (6) represents the beach profile during a storm, covered by even-laminated sands (7) deposited on the foreshore during high-energy condition. Unit $C$ (top) includes a very mature ridge, represented by low-angle cross-bedding (8) and the filling of runnel and vertical growth of berm recorded as even laminated sands (9). A small cliff (10) marks the present-day erosional surface of the berm.

(Fig. 5). During the last stages of accretion, the ridge gradually comes to play the part of a berm. The changes in hydraulic conditions involved make themselves felt specially on the seaward flank which quickly changes from convex-up to concave-up as a result of swash action. From this stage onwards, when ridge and berm completely melt together, water will cover the berm only exceptionally, viz. during spring high tides, especially if they are strengthened by wind set-up. As a result a further vertical accretion is progressively prevented.

As shown by Hine (1979), the internal structure of a berm is made up of a cyclic pattern of horizontal parallel laminations arranged in fining-up sequences which represent the transition from neap to spring tides. We found that this lateral succession of sequences tends to be overlain by seawardinclined parallel lamination also arranged in fining upward sequences (Fig. $3)$. 
The ideal sequence originating in meso-tidal coasts is thicker, and the individual structures often are repeated within each interval and, consequently, they have a more complex appearance than in the sequence built at micro-tidal coasts (Figs. 2 and 3 ).

\section{PRESERVATION POTENTIAL}

Preservation of the described features and the resulting sedimentary structures depends on several coastal factors that will be briefly discussed. Much of the inner structure of the ridge is eroded as it migrates: at the early stages of accretion, only the runnel sediments and the lower part of the ridge are likely to escape erosion; the more mature stages offer a better chance because they form the nucleus of the berm and more sediments come to rest on top of them. Thus, only the volume of sediment enclosed between the initial and final beach profiles will be preserved at the end of the migration of the ridge (Figs. 2, 3 and 5). Long-term preservation depends on the strength, frequency and angle of incidence of storms or strong swells which can greatly modify the topography of the beach by removing the ridges and severely eroding the berm. In the case of exposed high-energy coasts, few or no sedimentary structures tend to be preserved but for the even lamination produced by long-period waves during storms. Sequences approaching the ideal ones described above are likely to be preserved only on protected coasts. The orientation of the coast with respect to prevailing winds, thus, is of capital importance.

Prograding coasts with a high sediment supply are the favourable sites for the preservation of ridge structures as noted by Van den Berg (1977), Hine (1979) and Beets et al. (1981) among other authors. A sufficient supply of sediment and shelter from heavy storms appear to be of prime importance for a high preservation potential.

\section{CONCLUSIONS}

Comparison of the sedimentary structures generated by the migration of ridge and runnel systems revealed that the sequences found on mesotidal coasts are thicker and more differentiated than those found on microtidal coasts. The ideal sequence built on a microtidal coast (Fig. 2) consists of (from bottom to top): (1) cross-laminated sands (runnel facies); (2) crossbedded sands with local discontinuity surfaces (ridge facies); and (3) parallel-laminated sands inclined towards land and/or sea (berm facies).

By contrast, in the sequence that develops on a mesotidal coast (Fig. 3) the individual structures often are repeated within each interval, which results in a more complex appearance. From bottom to top, the sequence includes: (1) cross-laminated and cross-bedded sands associated with some mud drapes (runnel facies); (2) cross-bedding which may show strongly developed, horizontally laminated topsets. The sets often are separated into bun- 
dles of foresets, usually arranged in fining-upward sequences that are limited from each other by erosional discontinuity surfaces (ridge facies); and (3) parallel-laminated sands with variable dip directions, associated with small fining-up sequences (berm facies).

The preservation potential is directly related to a net supply of sediment and sheltex from heavy storms. Incomplete sequences may result as the effect of storms partly eroding the foreshore and berm.

\section{ACKNOWLEDGEMENTS}

Dr. J.R. Boersma (University of Utrecht) participated in the fieldwork and analysis of the ridge-berm sedimentation and reviewed the manuscript. Thanks are extended to Dr. T. Roep (University of Amsterdam) who provided an unpublished paper and kindly reviewed the manuscript.

\section{REFERENCES}

Beets, D.J.; Roep, T.B. and de Jong, J., 1981. Sedimentary sequences of the subrecent North Sea coast of the western Netherlands near Alkmaar. J. Sedimentol., Spec. Publ. I. Assoc. Sedimentol, $5,13 \mathrm{pp}$. (in press).

Dabrio, C.l. and Polo, M.D, 1981. Flow regime and bedfoms in a ridge and runnel system, SE Spain. Sediment, Geol., 28:97-109.

Dabrio, C.J., Boersma, J.R., Fernández, J., Martin, J.M, and Polo, M.D., 1980. Dinámica costera en el Golfo de Cádiz: sus implicaciones en el desarrollo socioeconómico de la región. I. Reunión Nal, Geol. Ambiental y Ord. Territ. $19 \mathrm{pp}$. (proceedings).

Davis JY., R.A., Fox, W.T. Hayes, M.O. and Boothroyd, J.C, 1972. Comparison of ridge and runnel systems in tidal and non-tidal environments, J. Sediment. Petrol., 42: $413-421$.

Doeglas, D.J., 1954. The origin and destruction of beach ridget. Leidse Geol. Meded, 20: $34-47$.

Hayes, M.O., 1972. Forms of sediment accumulation in the beach zone. In: R.E. Mayer (Editor), Waves on Beaches, 4. Academic Press, New York, N.Y., pp. 297-356.

Hayes, M.O. and Boothroyd, J.C., 1969. Storms as modifying agents in the coastal environment, In: Coastal Research Group, Coastal Environments, Northeastern Massachusetts and New Hampshire. Soc. Econ. Paleontol. Mineral., Field Trip Quidebook, Con. trib. no, 1. Dept, of Geol, Univ, Massachusetts, Amherst, Mass., pp. 245-265.

Hine, A.C., 1979. Mechanisms of berm development and resulting beach growth along a barrier spit complex. Sedimentology, 26: 333-351.

MoCave, I.N, and Geiser, A,C., 1978. Megaripples, ridges and rumnels on intertidal flats of the Wash, England, Sedimentology, 26: 352-369.

Owens, E.H, and Frobel, D.H., 1977. Ridge and runnel systems in the Magdalen Islands, Quebec, J. Sediment. Petrol., 47: 191-198.

Reading, H.G., 1978. Sedimentary Environments and Facies. Blackwell, London, 557 pp.

Reineck, H.E, and Singh, I.B., 1973. Depositional Sedimentary Environments, Springer, Berlin, 439 pp.

Roep, T.B., Beets, D.J. and Ruegg, G.H.J., 1975. Wave built structures in Subrecent beach barriers. IX Int. Congr. Sedimentology, Nice, Theme 6: 141-146 (abstracts).

Van den Bergh, J.H., 1977. Morphodynamic development and preservation of physical sedimentary structures in two prograding recent ridge and runnel beaches along the duteh coast. Geol. Mijnbouw, 56:185-202.

Wunderlich, F., 1972. Beach dynamies and beach development. Senckenbergiana Mar, $4: 47-79$ 